\title{
Modern problems of biological degradation of black earth and ways of preserving their fertility
}

\author{
S. Baliuk, \\ B. Nosko, \\ Academicians of the NAAS, Doctors of Agricultural Sciences \\ Ye. Skrylnyk, \\ Doctor of Agricultural Sciences \\ National Scientific Center "Institute of Soil Science and Agrochemistry named after O.N. \\ Sokolovsky »
}

The purpose. Determination of modern rates of biological degradation of black earth and other soils in conditions of intensification of farming agriculture and methods of its slowing down. Methods. Analysis of changes of the content of humus in soils of Ukraine as a whole and by results of long stationary experiments. Account of balance of nutrients and humus. Forecast of an exit of organic raw material and balance of organic substance in soils of Ukraine under different scripts. Results. Regularities of conversion of organic substance of black earth in different systems of farming agriculture are substantiated. Dependence of processes of mineralization on structure of sown areas and economic balance of nutrients in farming agriculture is considered. The generalized data are cited on dynamics of content of humus in a slit of regions and soilclimatic zones of Ukraine for the period of 1882-2010. They calculated that the positive balance of humus in soils of Ukraine is possible in conditions of engaging of all non-documentary part of crop and all sources of organic substance. Conclusions. By results of statistical data, biological degradation of soils is observed in all regions and native zones of Ukraine. It is proved that after ploughing virgin soil and paleocrystic long fallow, irrespective of fertilizer system of crops, in grain crop rotations the general content of humus in arable layer of typical black earth is diminished by $20-25 \%$. Accumulation of humus will be justified only in that event when it is more effective than other agrotechnical means and methods which improve soil characteristics limiting productivity of cultivated crops.

Key words: black earth, fertility, humus, mineralization and humification, crop rotations, balance, forecast.

Humus is the most important indicator of soil fertility, which determines the productivity of agricultural land. Its properties in the soil are related to structural properties, absorption capacity, buffering, water and physical properties. Humus is an important source of nutrients: in chernozem, it contains $98 \%$ of total nitrogen and more than $50 \%$ of phosphorus. It determines the magnitude of enzymatic activity, the production of carbonic acid in the surface layer of the atmosphere, is the largest source of accumulation of solar energy, that is, by definition V.A. Kovdri [4] performs a biosphere function.

The study of humus, as the most characteristic, specific part of the soil, is devoted to numerous works of domestic and foreign scientists, where the main laws of humus formation, nature and properties of humus are considered [3,11,13-16]. Recently, more and more attention is paid to the impact of plowing and agricultural use of soils on the content and quality of organic matter [6, 9].

The conducted researches testify to the close connection of harvests of crops with humus content. It is clear that humus does not affect the productivity of crops directly, but ultimately, this dependence is very high, and therefore humus is and will continue to be one of the most important indicators of the efficiency of soil fertility $[7,10]$.

Chernozems differ from other soils with high levels of potential fertility: large stocks of humus and nutrients, the most favorable for plants structure and water regime, mainly neutral reaction of soil solution, high biological activity. Chernozem on the territory of Ukraine has been formed over many millennia 
(according to various estimates from 5 to 10 thousand years) in an extremely favorable climate, forest soil crop rocks and mainly steppe vegetation [8]. Such conditions were in the past only in certain parts of the world, as evidenced by the area of chernozem in different countries. By this indicator (27.8 million hectares) Ukraine occupies the 4th place in the world after Russia (145, 4 million hectares), the USA (55.1 million hectares) and China (38 million hectares) [1] .

The introduction of chernozem into agricultural use has caused sharp changes and the ratio of practically all soil processes and properties: organic matter entering it and its mineralization, physical parameters (deterioration of structure) and water regime, acidification and decalcification. An analysis of the dynamics of all fertility indexes of chernozems after the plowing of virgin soil and its agricultural use indicates the degradation of soils, which is primarily due to the imbalance in the intake and mineralization of organic matter.

The purpose of the research establishment of modern rates of biological degradation of chernozems and other soils in conditions of intensification of agriculture and means of its deceleration.

Research methodology. In studies, the results of long-term dynamics of humus content in stationary experiments of the NSC «Institute for Soil Science and Agrochemistry Research named after O.N. Sokolovsky» and Mironovsky institute of wheat named after V.M. Remesla NAASU in the conditions of application of different fertilizer systems, as well as the data of the laboratory of organic fertilizers and humus on the long-term biological degradation (dehumidification) of soils in different soil-climatic zones and administrative areas.

Research results. The modern humus state of chernozem of arable land is the result of centuries-old evolution under the influence of human man's human activities. 100 years after V.V. Dokuchaev's experiments, the reduction of humus in the arable layer of the chernozem of the European part of the USSR, depending on the region and subtype, is $21-40 \%$, and its average annual losses-correspondingly $0.5-0.9$ t/ha $[7,10,12]$.

Loss of humus from the arable soil layer during their agricultural use mainly due to soil erosion and violation of the ratio of organic matter intake and its mineralization.

According to Bulugin S.Yu. [2], each year 500 million tons of soil is washed off from arable land of Ukraine, with which 24 million tons of humus are lost. The intense loss of humus in chernozems, especially in the first stages after their introduction into agricultural crops, is due to a decrease in the flow of organic matter to the soil, which causes imbalance in the processes of their mineralization and humification.

According to long-term data (18 rotations of five-way crop rotation), regardless of the fertilizer system, the total content of humus in the arable layer decreases by $20 \%$ compared with the virgin area (Table 1 ).

The calculations of the dynamics of the arrival of newly formed organic matter into the soil and its mineralization under separate crops in the crop rotation with two fields of sprout (sugar beet and corn) indicate that the balance of humus in the chernozem is typical in different ways, depending on the fertilizer system. The total amount of revenues in the soil of newly created humus due to the humification of nutrient residues for five crop rotations varies from 24.2 hectares on the control to 40.9 hectares in the variant with the organomineral fertilizer system (taking into account 140 tons per hectare of manure for all years ) In the version without fertilizer, the balance of humus during the five rotations of the crop rotation was negative, and its losses during this time reached $56 \mathrm{t} / \mathrm{ha}$, or 1.9 t/ha annually from a layer $0-60 \mathrm{~cm}$.

The main factor in adjusting the balance of humus is organic fertilizers: the introduction of manure (an average of 8 tons per $1 \mathrm{~g}$ crop rotation), especially when combined with mineral applications, at the end of the fifth rotation provided a positive balance of humus.

In the long-term experiment on the Korotichansky experimental field NSC «Institute for Soil Science and Agrochemistry Research named after O.N. Sokolovsky», established the dynamics of stocks and the balance of humus in chernozem typical of various agrochemical backgrounds for five rotations of six-grain cereal crop rotation after the plowing of a 50-year-old feather (Table 2). Characteristically, for the most part, the loss of humus in the arable layer is detected in all variants, and in the subterranean - the stock of humus increases. This proves indirectly that the root remains are rubberized at a depth of $0-60 \mathrm{~cm}$, as 
well as the presence of processes of movement of the newly formed humus in the soil profile, which, according to M.I. Laktionova [5], differs by a greater degree of mobility.

1. Effect of various fertilizer systems on the content of humus in chernozem typical (Research of the Mironovsky institute of wheat named after V.M. Remesla NAASU)

\begin{tabular}{|c|c|c|c|}
\hline \multirow[b]{2}{*}{ Version } & \multirow[b]{2}{*}{ Depth, sm } & \multicolumn{2}{|c|}{ Humus content, $\%$} \\
\hline & & general & $\begin{array}{l}\text { labile } \\
\text { (for Yegorov) }\end{array}$ \\
\hline \multirow{3}{*}{ Virgin } & $0-20$ & 4,7 & 0,16 \\
\hline & $20-40$ & 3,7 & 0,12 \\
\hline & $40-60$ & 3,3 & 0,07 \\
\hline \multirow{3}{*}{$\begin{array}{l}\text { Rally without fertilizers } \\
\text { (control) }\end{array}$} & $0-20$ & 3,6 & 0,14 \\
\hline & $20-40$ & 3,3 & 0,06 \\
\hline & $40-60$ & 2,4 & 0,03 \\
\hline \multirow{3}{*}{ Organic fertilizer system } & $0-20$ & 4,0 & 0,15 \\
\hline & $20-40$ & 3,5 & 0,08 \\
\hline & $40-60$ & 2,6 & 0,04 \\
\hline \multirow{3}{*}{ Mineral fertilizer system } & $0-20$ & 3,9 & 0,22 \\
\hline & $20-40$ & 3,3 & 0,08 \\
\hline & $40-60$ & 3,0 & 0,04 \\
\hline \multirow{3}{*}{$\begin{array}{l}\text { Organo-mineral fertilizer } \\
\text { system }\end{array}$} & $0-20$ & 3,9 & 0,38 \\
\hline & $20-40$ & 3,6 & 0,15 \\
\hline & $40-60$ & 2,9 & 0,04 \\
\hline
\end{tabular}

When the virgin (perehloga) is grown with an arachnoid layer, the very upper layer $(0-5 \mathrm{~cm})$ is mixed, enriched not only by the actual humus, but by the steppe furrow contained on its surface. On the background of such an enrichment of the arable layer, an organic substance capable of rapid mineralization, and increasing the humidality of arable chernozem in comparison with the whole, accelerates the process of decomposition. However, simultaneously with the intensification of mineralization processes throughout the layer, there is simultaneously the humification of organic matter, which is characterized by greater mobility and the ability to move in the soil profile. The most varied changes in its content occurred during two rotations, and later there is a stabilization and some increase in the layer of $30-60 \mathrm{~cm}$.

After cultivating different crops in fields, the unequal amount of organic remains remains. According to our data, the average annual revenues to the soil of newly formed organic substances due to the humification of organic residues in non-fertilized variants are: for winter wheat $-9.9 \mathrm{c} / \mathrm{ha}$, barley -6.8 , corn - 11.8, sugar beet - $2.9 \mathrm{c} / \mathrm{ha}$.

2. Stocks dynamics: the balance of humus in typical chernozem $(0-60 \mathrm{~cm})$ in different agrochemical backgrounds for five rotation of grain-growing crop rotation after the plowing of the flood, tha.

\begin{tabular}{|c|c|c|c|c|c|c|c|}
\hline \multirow{3}{*}{ Version } & \multicolumn{5}{|c|}{ Humus reserves, $\mathrm{t} / \mathrm{ha}$} & \multicolumn{2}{|c|}{ Losses } \\
\hline & \multirow{2}{*}{$\begin{array}{l}\text { Before } \\
\text { the } \\
\text { plowing }\end{array}$} & \multicolumn{3}{|c|}{ Got into the soil of organic matter } & \multirow{2}{*}{$\begin{array}{l}\text { At the } \\
\text { end of } \\
\text { the fifth } \\
\text { rotation }\end{array}$} & \multirow{2}{*}{$\begin{array}{l}\text { Of all } \\
\text { t/ha }\end{array}$} & \multirow{2}{*}{$\begin{array}{l}\text { On } \\
\text { average } \\
\text { per year, } \\
\text { t/ha }\end{array}$} \\
\hline & & $\begin{array}{l}\text { With plant } \\
\text { remains }\end{array}$ & $\begin{array}{l}\text { With } \\
\text { manur } \\
\mathrm{e}\end{array}$ & Of all & & & \\
\hline Fallow & 290 & - & - & - & - & - & - \\
\hline
\end{tabular}




\begin{tabular}{|l|l|l|l|l|l|l|l|}
\hline $\begin{array}{l}\text { Annual plow of } \\
\text { fertilizers } \\
(30 \text { years })\end{array}$ & - & 24,2 & - & 24,2 & 234 & 56 & 1,9 \\
\hline Manure, 140 t/ha & - & 25,7 & 7,6 & 33,3 & 260 & 30 & 1,0 \\
\hline $\begin{array}{l}\text { Manure, 140 t/ha }+ \\
\text { 2NPK }\end{array}$ & - & 33,3 & 7,6 & 40,9 & 298 & +8 & $+0,3$ \\
\hline
\end{tabular}

Fructose crops, especially sunflower, sugar beet provide the least amount of plant residues, therefore, in agro-permeable crop rotations, depending on their share in the structure of crops, losses of humus increase.

According to general data, with an increase in the saturation of crop rotation with crop growth by $10 \%$, the average annual losses of humus in the arable layer are increased by $0.2 \mathrm{t} / \mathrm{ha}$, and in crop rotation from 40 to $50 \%$ of such crops reach $0.7-0.9$ t/ha. The positive effect of crops on the content of organic matter in the soil is weakened in the series "perennial grasses - cereal cereal - breeding - steam". Accordingly, in this series losses of humus increase.

The results of the dynamics of humus content, obtained in stationary studies, are fully supported by generalized statistical data on the biological degradation of soils in Ukraine (Table 3).

In the period from 1882 (the study of V.V. Dokuchaev) by 2010 (aggregated data DA «Institute of Soil Conservation»), the content of humus in the forest-steppe zone, in which the black soil is dominant in the soil, has decreased from 4.51 to 3.19 , And in the Kharkiv region - from 7.0 to $4.2 \%$. The lowest losses of humus during this period were observed in Polissya (from 2.44 to $2.24 \%$ ), which can be explained by a higher proportion of organic fertilizers in the fertilizer system.

\section{Dynamics of humus content in soils of Ukraine}

\begin{tabular}{|l|l|l|l|l|}
\hline \multirow{2}{*}{ Zone } & Content, \% & \multicolumn{4}{l|}{} \\
\cline { 2 - 5 } & 1882 & 1961 & 1991 & 2010 \\
\hline Polissya & 2,44 & 2,30 & 1,98 & 2,24 \\
\hline Forest-steppe & 4,51 & 3,81 & 3,52 & 3,19 \\
\hline Steppe & 4,49 & 3,96 & 3,63 & 3,40 \\
\hline In Ukraine & 4,17 & 3,64 & 3,23 & 3,14 \\
\hline
\end{tabular}

The general tendency in recent years (1985-2014) is the reduction of production and use of organic fertilizers. In 2014, the output of manure and litter in agricultural enterprises was only 38.8 million tons, which could provide organic fertilizers per hectare of sown area of 2 tons. For a simple reproduction of soil fertility, it is necessary to add $8-10$ t/ha (in 1985, they received more than 250 million tons). The introduction per hectare of arable land (on average) decreased from $9.4 \mathrm{t} /$ ha in 1985 to $0.5 \mathrm{t} / \mathrm{ha}$ in 2014 , the reduction of organic fertilizers and under the main crops has decreased significantly. It is clear that such a sharp drop in the use of organic fertilizers greatly contributed to an increase in the negative balance of humus in all regions of Ukraine.

According to statistical data, the output of organic raw materials is forecast, and the possible balance of humus in different scenarios (Table 4 and 5).

Another, not less important factor affecting its indicators is the system of intensification of agriculture in the areas used for the production of agricultural products agroholdings. The actual state of agricultural production in farms subject to agroholdings indicates a systematic violation of the structure of the crop area, primarily due to the virtually unlimited increase in crop sown crops - sunflower and corn - and other exports of oriented crops (Table 6). 
4. Forecast of possible output of organic raw materials in Ukraine

\begin{tabular}{|l|l|}
\hline Indicator & Quantity \\
\hline Total sown area in agricultural enterprises, ths. ha & 18962,4 \\
\hline Production of organic fertilizers in agricultural enterprises (statistics), ths. Tons & 38800,00 \\
\hline Forecast introduction of organic fertilizers per 1 ha, t & 2,0 \\
\hline Output of non-part of the harvest, ths. $\mathrm{t}$ & 101538,00 \\
\hline Forecasting of the unproductive part of the crop on 1 ha of sown area, $\mathrm{t}$ & 5,4 \\
\hline Projection of sapropel on 1 ha, $\mathrm{t}$ & 2,4 \\
\hline Forecast introduction of peat per 1 ha, $\mathrm{t}$ & 0,02 \\
\hline Total yield of organic raw materials, ths. $\mathrm{t}$ & 186628,00 \\
\hline $\begin{array}{l}\text { The total forecast is the possible introduction of organic fertilizers per 1 ha of sown area, } \\
\mathrm{t}\end{array}$ & 9,8 \\
\hline
\end{tabular}

\section{Estimated possible balance of humus in soils of Ukraine}

\begin{tabular}{|l|l|}
\hline Indicator & Quantity \\
\hline $\begin{array}{l}\text { Actual balance of humus in the case of introduction of } 0.4-0.5 \mathrm{t} / \text { ha of organic fertilizers } \\
\text { per } 1 \text { hectare of sown area (without making an uncommon part of the harvest), } t / \text { ha }\end{array}$ & $-1,22$ \\
\hline $\begin{array}{l}\text { Balance of humus in the case of earnings in the soil of the whole unproductive part of } \\
\text { the harvest, } t / \text { ha }\end{array}$ & $-0,14$ \\
\hline $\begin{array}{l}\text { Balance of humus in the case of earnings in the soil of all non-consumable part of the } \\
\text { harvest and the introduction of organic fertilizers, } t / \text { ha }\end{array}$ & 0,17 \\
\hline $\begin{array}{l}\text { Humus balance in the case of attracting all the organic raw materials (manure, litter, } \\
\text { non-product crops, sapropel, peat), t/ha }\end{array}$ & 0,65 \\
\hline
\end{tabular}

In addition, one of the most important laws of agriculture, established in the first century. A well-known German scientist Y. Lybich, according to which, in order to maintain the fertility of the soil, the farmer must annually return to the soil the amount of nutrients that are cropped by crops.

A typical example of this state of affairs is the results of the analysis of data on yields of main crops (winter wheat, maize for grain, barley, sunflower and sugar beet) as of 1october, 2014, which are submitted by the NSC «Institute for Soil Science and Agrochemistry Research named after O.N. Sokolovsky», and the balance of nutrients calculated on their basis.

\section{Structure of sown areas in Ukraine, \% *}

\begin{tabular}{|l|l|l|}
\hline Cultures & 1990 & 2013 \\
\hline Cereals and legumes & 36,5 & 41,5 \\
\hline Corn for corn & 8,5 & 17,5 \\
\hline TexHiчHi Technical & 11,6 & 27,3 \\
\hline Vegetables and potatoes & 6,4 & 6,5 \\
\hline Fodder (without perennials) & 24,7 & 3,8 \\
\hline Perennial grasses & 12,3 & 3,7 \\
\hline
\end{tabular}

${ }^{*}$ Published statistics

To determine the nutrient balance, average yields across Ukraine as a whole were taken, as well as the maximum values achieved in the entire area of crops in some areas. The number of fertilizers applied to individual crops is calculated as the average for $2011-2013$.

For the average winter wheat yield in Ukraine (as of october 1, $2014-4.13 \mathrm{t} / \mathrm{ha}$ ), the balance (excess of removal over the amount of nutrients added to the soil) is about nitrogen - $81 \mathrm{~kg} / \mathrm{ha}$, phosphorus - 39 and potassium - $59 \mathrm{Kg} / \mathrm{ha}$, in the amount of negative balance reaches $179 \mathrm{~kg} / \mathrm{ha}$ of the active substance. 
In some areas, the winter wheat harvest reached 5.52 tons/ha, which respectively increased the nutrient deficiency, which was 116 for nitrogen, 51 for phosphorus and 71 for potassium, and $238 \mathrm{~kg}$ for hectare.

Even more impressive figures were obtained for corn for grain: at an average yield of $4.93 \mathrm{t} / \mathrm{ha}$, the nitrogen deficit was $78 \mathrm{~kg} / \mathrm{ha}$, phosphorus - 36 and potassium - 166, and in the amount of $230 \mathrm{~kg} / \mathrm{ha}$. The maximum yields of corn in some areas over the entire crop area reached 8.09 tons per hectare. The deficit of the nutrient balance for such a crop is: nitrogen $172 \mathrm{~kg} / \mathrm{ha}$, phosphorus - 67 and potassium 198 , and in the amount of $437 \mathrm{~kg} / \mathrm{ha}$.

A very large deficit of nutrients was found in areas under sunflower. According to the average yields in Ukraine (as of October 1, $2014-1.99$ tons/ha), the balance of nitrogen balance is $92 \mathrm{~kg} / \mathrm{ha}$, phosphorus 47 and potassium - 220, and in the amount of $359 \mathrm{~kg} / \mathrm{ha}$. And in the background of the harvest of 2.87 t/ha in certain areas, the excess of removal of nutrients compared with their arrival in the soil reaches critical points: nitrogen - $142 \mathrm{~kg} / \mathrm{ha}$, phosphorus - 73 and potassium - 320. The total deficit of nutrients for such a crop Reaches $535 \mathrm{~kg} / \mathrm{ha}$, that is, more than $0.5 \mathrm{t} / \mathrm{ha}$.

The deficit of nutrients in 2014 was also detected in relation to other crops (barley, rape, sugar beet).

At the expense of which resources is covered by this deficit? In the vast area of agricultural land (except for sandy and sandy soils of Polissya), the gross potassium content in soils varies from 1.8 to $2.2 \%$, depending on the mineralogical composition of the soil forming species, which is generally satisfactory for most crops (except for sunflower and sugar beet).

Nitrogen and phosphorus in soils are of biological origin and are mainly contained in humus. Plants for nutrition use only the mineral (most soluble) forms of nitrogen and phosphorus, which enter the soil solution after the mineralization of humus, which facilitates the transition to an accessible state of the elements fixed in the organic matter.

In order to compensate for the shortage of nitrogen balance that arose for winter wheat, barley, sugar beet and sunflower in the medium-sized crops in Ukraine, the average salinity of humus in soils is about 1 t/ha, with $50 \%$ of the by-products of grain cereal (straw) and $100 \%$ Vegetable remnants of other crops (basil, etc.). At maximum yields of these crops humus loss to compensate for nitrogen deficit reaches about $1.5 \mathrm{t} / \mathrm{ha}$.

In order to reduce humus losses due to mineralization, it is necessary to review the structure of the crop area in order to reduce the proportion of crop rotation. In crop rotation with perennial herbs and plowing the entire mass of by-products it is possible to achieve a deficit-free balance of humus even without the use of organic fertilizers [7].

Among the measures to increase the flow of organic matter to the soil, in addition to optimizing the structure of crops and the use of manure, the most accessible for widespread introduction is the plowing of post-dormancy remains and, above all, straw of winter wheat. The calculated calculations show that the average yield of winter wheat is a total straw output of 32.7 million tons. If we take the conventional share of by-products that will be used for fertilizers ( $45 \%)$ according to the nutrient content of straw, it will reach the soil (for medium yields): Nitrogen - 66 ths. t, phosphorus - 29 and potassium - 132 ths.t. In addition, 5.9 million tons of carbon will be added to the soil from the straw, which will provide 3.4 million tons of newly created organic matter.

In the case of maximum winter wheat yields (5.52 tons/ha), straw output will reach 44.0 million tons, with 89 thousand tons of nitrogen, 40.0 thousand tons of phosphorus, 178.0 thousand tons of potassium and 7.9 million tons of carbon, which will provide 4.6 million tons of newly created organic matter.

Scientifically grounded application of straw as an organic fertilizer positively affects the humus soil condition. It has been established that 37.0 centimeters of straw are equivalent to 100.0 centners of litter manure or 270.0 centners of green fertilizer. It is estimated that 5 centner/ha of organic matter comes from 50,0 centners/ha of straw dry matter, with 10,0 centners/ha of cultivars and 4 centners per hectare of root crops [10].

On average, $90 \%$ of the fresh organic material entering the soil is mineralized to the final products, and only $10 \%$ is involved in the synthesis of humus compounds, or is fixed in soil in stable forms. It is established that in 2,5-4 months, decomposes up to $46 \%$ straw, in $1,5-2$ years - up to $80 \%$, the rest later. 
When wrapping straw in the soil, it is necessary to add 10-12 $\mathrm{kg}$ of active nitrogen per ton of straw. This contributes to the improvement of microorganisms and the increase in the number of newly created humus substances.

At the same time, the use of straw for soil fertilization will not be able to restore effective fertility, which is systematically reduced due to violation of the main agricultural laws of agriculture by land users. The over-saturation of the structure of the sown areas by the spreading crops (mainly corn and sunflower), a large deficit of nutrient balance, and the reluctance to develop a livestock sector, which, in addition to the corresponding products, could provide an increase in manure production volumes, on the background of not perfectly monitoring the soil fertility condition, causes irreversible processes Soil degradation, which will sooner or later lead to deterioration of the most important elements of fertility. Currently, high yields of agricultural crops are obtained using the high natural fertility of Ukrainian chernozems, but the question arises: what will happen to the fertility of the soil after 5-10 years? How much then will it be necessary to invest in order to receive even this year's harvests? Obviously, today it is necessary to take into account the processes that take place in our most fertile soils and make radical decisions on the implementation of a scientifically grounded "Soil Fertility" program, which has long been developed in the NSC «Institute for Soil Science and Agrochemistry Research named after O.N. Sokolovsky».

What should be the strategy and tactics of farmers in relation to the reproduction of humus in soils of agrocenoses? Two different situations need to be borne in mind: the first one - when using the benefits of more humus soil after plowing a virgin or a perennial, the second - in the event of an attempt to create these benefits through special measures. In the first case, the natural resource is spent, in the second one - it is necessary to compare the costs of humus accumulation with the benefit that this accumulation can provide.

Fertility management is to consistently improve the properties of the soil in accordance with the plant nutrition level. In this approach, fertility increases as a result of growing crop yields. Consequently, the soil fertility management system becomes an integral part of the agrophytocenose productivity management system. The accumulation of humus will be justified only if it is more effective than other agricultural techniques and techniques will improve the soil properties, which limit the productivity of crops grown.

The use of special measures for the accumulation of humus - the introduction of smoothing doses of organic fertilizers or the transfer of soil to the fog - can only be considered for soils where the humus content has fallen below the critical level. Soil fertilization, the humus content of which exceeds the critical level, should be carried out within the framework of a rational system of agriculture, which is aimed at maximizing profits for the preservation of the sustainable functioning of the agro-landscape and the elimination of environmental changes in the environment.

\section{Conclusions}

According to the results of statistical data, biological degradation of soils is observed in all regions and natural zones of Ukraine. For the period from 1882 to 2010, the average weight of humus decreased in Polissia from 2.44 to $2.24 \%$, forest-steppe - from 4.51 to $3.19 \%$, in the Steppe - from 4.17 to $3.14 \%$.

According to the generalized data of long experiments after the plowing of virgin forests and perennial forests, irrespective of the system of fertilization of crops in grain-growing crop rotations, the total content of humus in the arable layer of black currant is reduced by $20-25 \%$.

The main measures that will make it possible to suspend dehumidification of soils are: reconstruction of crop rotation in the direction of increasing the share of crop of continuous sowing and perennial grasses and reducing sunflower and corn crops; Use of organic fertilizers of post-dormancy grains and straw of cereals; Application of all kinds of carbonaceous raw materials (manure, litter, peat, sapropel, etc.).

The use of special measures for the accumulation of humus - the introduction of smoothing doses of organic fertilizers or the transfer of soil to the fog - can only be considered for soils where the humus content has fallen below the critical level. Soil fertility management, the content of humus in excess of the 
critical level, should be carried out within the framework of a rational system of agriculture, which is aimed at maximizing the profit for maintaining the sustainable functioning of the agrolandscape.

Nowadays, as never before, it is urgent and appropriate to return to the discussion on the establishment of a land protection service in the country, which would combine the efforts of various departments to develop and implement a fundamentally new approach - sustainable (efficient and economical) land use.

\section{Bibliography}

1. Baliuk S.A. Ukraine's soil resources: state and measures to improve them/S.A. Baliuk/Visnik agrar. nauki. - 2010. - № 6. - P. 5-10.

2. Buligin S.Yu. Formation of environmentally sustainable agro-landscapes/S.Yu. Buligin. - K, HDAU. $-2001 .-$ P. 113.

3. Degtyarov V.V Humus of Chernozem Forest-Steppe and Steppe of Ukraine: Monografiya/za red. D.G. Tihonenka. - HNAU Imeni V.V. Dokuchaeva. - H.: Maydan, 2011. - P. 360.

4. Kovda V.A. Problems of protecting the soil cover and the planet's biosphere/V.A. Kovda. - Izd. AN SSSR, Puschino, 1989. - P. 155.

5. Laktionov N.I. Agricultural use of soils and colloidal humus/N.I. Laktionov//Trudyi HSHI, 1970. T.139.- P. 9-15.

6. Nosko B.S. Anthropogenic evolution of chernozems/B.S. Nosko. - X.: vid. «13 tipograflya». - 2006. P. 239.

7. On the state of soil fertility in Ukraine: a national report/[S.A. Baliuk, V.V. Medvedev, O.G. Tarariko ta in.]. - K., 2010. - P. 111.

8. Samoylova E.M. The origin of chernozems/E.M. Samoylova - V kn. «Russkiy chernozem. 100 let posle V.V. Dokuchaeva». - M.: Izd-vo «Nauka», 1983. - P. 28-36.

9. Skrylnyk Ye.V. Transformation of soil humus soil and its energy intensity under the influence of various fertilizer systems/Ye.V. Skrylnyk/Visnik tsentru naukovogo zabezpechennya APV Harkivskoi oblasti. - 2010. - Vip. № 7. - P. 184-194.

10. Strategy of balanced use, reproduction and management of Ukrainian soil resources/in the sciences. Ed. S.A. Baliuk, V.V. Medvedev. - K.: Agrarna nauka, 2012. - P. 240.

11. Tyurin I.V. Organic matter of soil and its role in fertility/I.V. Tyurin. - M.: nauka, 1985. - P. 302.

12. Chesnyak G.Ya. Contemporary ideas about the potential and effective fertility of soils/G.Ya. Chesnyak, V.D. Muha//Kn Rodyuchist Gruntiv. Monitoring ta upravlinnya. - K: Urozhay, 1992. - P. 5-12.

13. Sharkov I.N. The concept of humus reproduction in soils/I.N. Sharkov//Agrohimiya. - 2011. - № 12. - P. 21-27.

14. An integrative approach of organic matter stabilization in temperate soils: Linking chemistry, physics, and biology/l Kögel - Knabner, K.Ekschmitt, H.Flessa et al.//J.Plant Nutr.Soil Sci. - 2008. V.171. - P.5-13.

15. Fate of soil-applied black carbon: downward migration, leaching and soil respiration/J.Major, J.Lehmann, M.Rondon, C.Goodale//Glob.Chan.Boil. -2010. - V.16. - P.1366-1379.

16. Murage E. Distribution of organic carbon in the stable soil humic fractions as affected by tillage management/E. Murage, P. Voroney//Canad. J. Soil Sci. - 2008. - V. 88. - № 1. - P. 99-106. 